\title{
Farklı Toparlanma Uygulamalarının Yüzücülerde Laktik Asit Düzeyine Etkisinin İncelenmesi
}

\section{Analyzing The Effect Of Different Recovery Implementations Upon Blood Lactic Acid Level and Hearth Rate On Swimmers}

\author{
Rifat SARI ${ }^{1}$, Erkan DEMIRKAN ${ }^{2}$, Mustafa KAYA ${ }^{1}$
}

1 Amasya Universitesi Sosyal Bilimler Enstitüsü Beden Eğitimi ve Spor-Amasya

2 Hitit Unniversitesi Beden Eğitimi Spor Yüksekokulu - Çorum

3 Gaziosmanpaşa Üniversitesi Beden Eğitimi Spor Yüksekokulu - Tokat

ÖZET

Bu çalışmanın amacı, yüzücülere uygulanan yüklenme sonrasında farklı toparlanma yöntemlerinin kan laktik asit ve kalp atım sayısına olan etkilerini araştırmaktır.

Araştırmaya Tokat Gaziosmanpaşa Üniversitesi Beden Eğitimi Spor Yüksekokulu Antrenörlük Eğitimi Bölümü öğrencilerinden, yüzme uzmanlık dersi alan 15 erkek sporcu katılmıştır. Sporculara yaptırılan yüzme antrenmanlarından sonra aktif ve masaj ile dinlenme yöntemi uygulanmıştır. Testten önce, testten hemen sonra ve test bitiminin 5.dk. 10. dk ve $20 \mathrm{dk}$. sında sporcuların kalp atım sayısı ile kan laktik asit ölçümleri yapılmıştır

Verilerin değerlendirilmesinde SPSS 20.0 programı kullanmıştır Dinlenme protokollerinin laktik asit ve kalp atımındaki farklılığı bulmak için bağımlı gruplarda tekrarlayan ölçümlerde iki yönlü varyans analizi (FRIDMAN) testi uygulandı. Anlamlılık düzeyi olarak 0.05 kabul edildi.

Sonuç olarak Araştırmamızda uygulanan testin 5.dakikasında, 10.dakikasında ve 20.dakikasında laktik asit miktarı anlamlı bir şekilde azalma olduğu tespit edilmiştir. Yüklenme sonrası laktik asit miktarında ilk 10 dakikadaki düşüşün 20.dakikaya göre daha fazla olduğu görülmüştür. Farklı dinlenme yöntemlerinin laktik asit miktarı ve kalp atım sayısı üzerine etkilerine baktığımızda test sonrası 5 dk., $10 \mathrm{dk}$. ve $20 \mathrm{dk}$. lar arasında anlamlı farklılığın olmadığı, test öncesi değerler ile test sonrası, $5 \mathrm{dk}$., $10 \mathrm{dk}$. ve $20 \mathrm{dk}$. lar arasında anlamlı fark olduğu görülmektedi

Anahtar Kelimeler: Anaerobik eğzersiz, Kan laktik asit, Fizyolojik toparlanma, yüzme
The purpose of this study was to analyze the effect of different recovery methods after overloading implemented to swimmers upon blood lactic acid and hearth rate.

Totally 15 sportsmen taking swimming expertness course studying at Tokat Gaziosmanpaşa University Physical Education and Sports Vocational School were included. After the swimming trainings performed by the sportsmen, active and massage resting method was administered. Before the test, soon after the test and 5 minutes, 10 minutes, 20 minutes after the test, hearth rate and blood lactic acid measurements of the sportsmen were carried out.

In analysis of the data, SPSS 20.0 software was benefited. Fridman repeated measures analysis of variance in the dependent variable was used. Statistical significance was set at level of $p<0.05$.

Consequently, it was determined that there was a significant decrease at lactic acid amount at the 5th minute, 10th minute and 20 minute of the test. It was noticed that, the decrease at lactic acid amount in the first 10 minutes was more than the one in the 20th minute after overloading. When the effect of different resting methods upon lactic acid amount and hearth rate was analyzed, it was found that there was no significant difference between post-test 5th minute, 10th minute and 20th minute, and there was a significant difference between pre-test values and post-test 5 th minute, 10th minute and 20th minute values.

Key Words: Anaerobic exercise, Blood lactic acid, Physiologic recovery, Swimming 


\section{GíRiş}

Sporun; günümüzde insanların fiziksel, zihinsel, fizyolojik, sosyal, sağlık açısından önemi herkes tarafından bilinmekte ve kabul görmektedir. Fertlerin sportif aktivitelere direkt veya dolaylı katılımlarının her geçen gün artması, spora karşı ilginin de aynı şekilde artmasına yol açmaktadır (7).

Bugünkü ihtisaslaşmalar her spor dalı için değişik antrenman programları ve sporcu tipleri gerektirmektedir. Spor bilimcileri, sportif aktivite de bulunan ve performans sporlarıly uğrasan tüm sporcuların uğraştıkları spor dallarında daha başarılı olabilmeleri amacıyla sürekli yeni arayışlar içindedir. Bir yandan sporcuların psikolojik, sosyolojik, ergojenik, fizyolojik ve benzeri alanlarda etkilenebilecekleri her türlü olumsuzluğu ortadan kaldırmaya çalışırken, diğer yandan da performanslarını arttırabilmek yolunda büyük bir yarış içindedirler(7).

Daha iyi antrenman, beslenme, dinlenme vb. metotların geliştirilmesi, bilimsel sistemlere dayandırılması, egzersiz şiddetlerinin ve sürelerinin arttırılması ile günümüzde bütün rekorların pes peşe kırılmaları sağlanmıştır.

Sporcuların egzersize başlamaları anında, bir dizi iletinin oluşumu sonucu kaslarında uyarılma, kasılma ve güç oluşur. Bu gücün oluşumunda gerekli olan enerjinin temin ediliş şekli eğzersizin süresine ve şiddetine bağlı olarak değişmektedir. Fiziksel aktivite anında sporcuların ihtiyacı olan enerji, kaslarında sınırlı olarak bulunan ATP'nin parçalanması sonucunda elde edilir. Egzersizin devam edebilmesi için kullanılan ATP'nin kaslara tekrar kazandırılması bu kazanımın gerçekleştirilebilmesi için ise, aerobik ya da anaerobik yoldan bu enerjinin temin edilmesi gerekmektedir (7).

Egzersizin şiddetine bağlı olarak aerobik metabolizmanın sınırlarının aşılması glikoliz hızını arttırır, bunun sonucunda ise laktik asit oluşur. Laktik asit oluşumu ile birlikte $\mathrm{PH}$ düşer, $\mathrm{PH}^{\prime}$ düşmesi kas kasılmasını etkiler ve fosforuktakinaz enzim inbibasyonuna neden olur. Glikoliz yavaşlar ve enerji veren metobolitler azalır. Kas ve kanda biriken laktik asit ise yorgunluğa yol açar ve sporcunun performansı düşer.
$\mathrm{Bu}$ durumda laktik asitin vücuttan uzaklaştırılması için dinlenme kaçınılmaz hale gelir (7).

Egzersiz sonrasında ise metabolik artıkların uzaklaştırılması, enerji maddelerinin yeniden sentezlenmesi, su elektrolit dengesinin sağlanması, vücut sıcaklığının ve oksijen tüketiminin düşürülmesi gibi birçok faktöre bağlı olarak toparlanma geçekleşmektedir. Yüksek şiddetteki yüklenmeler sonrasında toparlanma oranı interval çalışmalardaki performans devamlılığının sağlanması açısından önem taşımaktadır (14).

Egzersiz sonrası toparlanmanın amacl, organizmayı dinlendirmek veya egzersizden önceki şartlara yeniden hazırlanmaktır. Toparlanma, organizmanın antrenmanlar arasında yenilenme oranını hızlandırır, yorgunluğu ve sakatlanma riskini azaltır. Laktik asit yorgunluğa neden olan en önemli faktörlerden birisi olduğundan, toparlanma veya dinlenme, vücuttaki laktik asidin azalmasıyla baslar. Maksimal bir egzersizden sonra kan ve kasta oluşan laktik asidin uzaklaştırılması, pasif dinlenme ile yaklaşık 2 saat, aktif dinlenmede ise 1 saat kadar sürer (9).

Bilindiği üzere, ferdi olarak yapılan sporlarda yarışma süresi belirlenmiştir. Ancak bazı sporlarda bir gün içinde birden fazla müsabaka yapılmakta ve müsabaka araları kısa olabilmektedir. Zorlu müsabakalardan çıkmış sporcuyu yeni müsabakaya kadar dinlendirmek, yorgunluk belirtilerini ortadan kaldırıp toparlanmayı sağlamak gerekmektedir. Bu toparlanma ne kadar iyi ve çabuk olursa, bir sonraki müsabakaya sporcu daha zinde ve iyi bir performansla çıkarak başarıyı yakalayabilecektir $(12,1)$.

$\mathrm{Bu}$ araştırmanın amacı anaerobik eğzersiz sonrasında vücutta biriken laktik asit (yorgunluğun) azalmasında farklı toparlanma uygulamalarının etkisinin olup olmadığı ve hangi toparlanmanın laktik asiti (yorgunluğu) düşürmede daha etkili bir yöntem olduğu araştırılmıştır. 


\section{YÖNTEM}

\section{Araştırma gurubu}

$\mathrm{Bu}$ araştırma dizaynında sporcuların 2 farklı toparlanma (Aktif ve Masaj) uygulamasının vücuttaki etkileri ve fizyolojik toparlanmaya ne kadar etkili olduğu araştırılmıştır. Araştırma 5 dk. ısınma koşusundan sonra dinlenik durumda, yüklenmeden önce, yüklenmeden hemen sonra, yüklenmeden 5. dk. , 10. dk. ve 20. dk. sonra kalp atım sayısı alınarak ve kan laktik asit ölçümü yapılarak gerçekleştirilmiştir.

Araştırmaya katılan gönüllü grup Tokat Gaziosmanpaşa Üniversitesi Beden Eğitimi Spor Yüksekokulu Antrenörlük Eğitimi Bölümü öğrencilerinden, yüzme uzmanlık dersi alan 15er- kek sporcudan oluşturuldu. Sporculara çalışma başlamadan önce yapılacak antrenmanlar ve ölçümlerle ilgili gerekli olan bilgilendirme yapıldı. Gönüllülerin çalışmadan önce beslenmelerine dikkat etmeleri ve dinlenmiş şekilde gelmeleri sağlandı.

\section{Ölçüm Metotları}

Gönüllülerin ağırlık ölçümünde standart, elde taşınabilen baskül, boy ölçümleri için ise (SecaAlmanya) marka boy ölçüm cihazı kıllanıldı. Kalp atım sayıları elektronik sinbo marka tansiyon aleti ile alındı. Kalp atım sayısı ölçümleri her dinlenme yöntemi için testten önce, testten hemen sonra ve test bitiminin 5.dk. 10. dk ve 20 dk. sın- da alınarak yapıldı.

Kan laktik asit ölçümü ise, kan laktat analizörü (Lactateplus) ve strips kullanılarak yapıldı. Ölçüm için parmak ucundan alınan kan, stripslere damlatılarak, kan laktat analizörü laktat plus ölçüm çihazında laktat oksit tekniği kullanılarak anında analiz edildi. Kan laktik asit ölçümleri her dinlenme yöntemi için testten önce, testten hemen sonra ve test bitiminin 5.dk., 10. dk. ve $20 \mathrm{dk}$. alınarak yapıldı.

Testin aktif dinlenme ve masaj uygulamaları ile kan tahlilleri Gaziosmanpaşa Üniversitesi Yarı Olimpik yüzme havuzunda yapıldı. Araştırmada yüzme sporcularına farklı haftalarda aynı anaerobik yüzme antrenmanı uygulanarak yüklenme öncesi, yüklenme sonrasını takiben $5 \mathrm{dk}$. $10 \mathrm{dk}$.ve 20. dakikalarda aktif dinlenme ve masaj ile toparlanma sonrasında laktik asit düzeyleri ve kalp atım sayısı ölçümleri alındı.

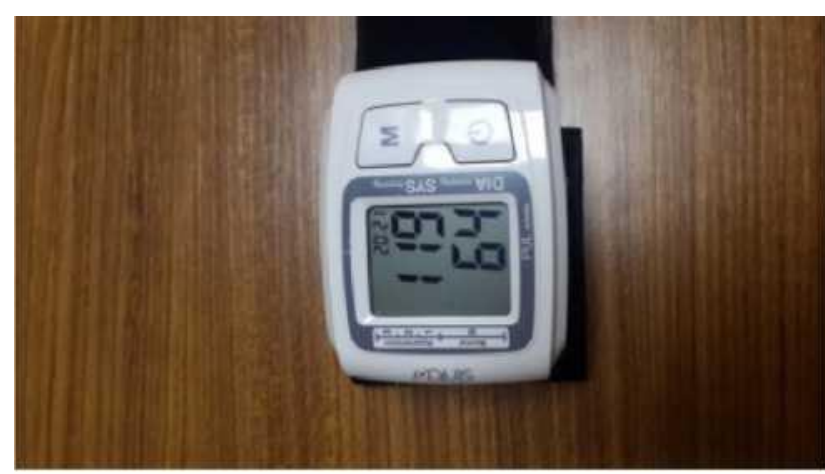

Resim 1. Dijital tansiyon ölçer.

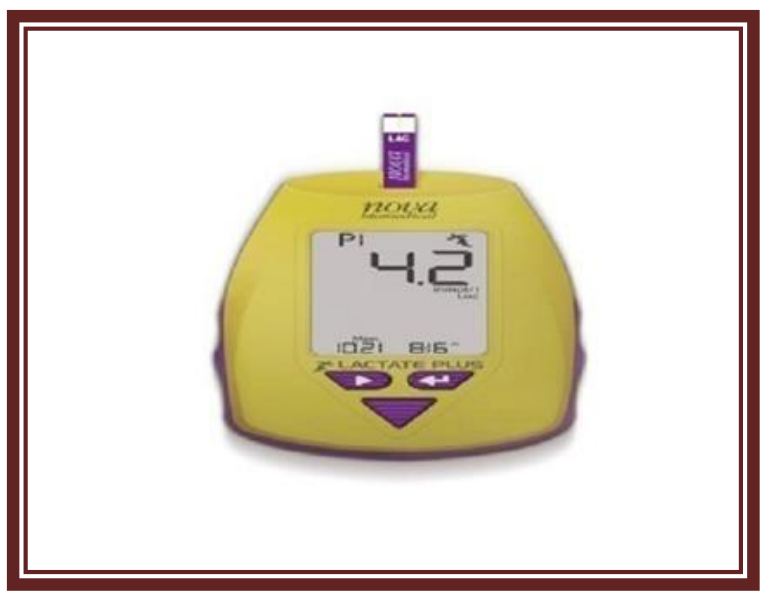

Resim 2. Kan laktik asit analizatörü

\begin{tabular}{|c|l|l|l|}
\hline \multicolumn{3}{|c|}{ Tablo I. Sporculara uygulanan antrenman programı. } \\
\hline & Yüzülen Mesafe & $\begin{array}{l}\text { Yüklenme } \\
\text { Şiddet }\end{array}$ & $\begin{array}{l}\text { Dinlenme } \\
\text { Aralığı }\end{array}$ \\
\hline 1 & Isınma (5 dk.) & & \\
\hline 2 & 200 m. serbest yüzme & $(\% 50-60)$ & $3 \mathrm{dk}$ \\
\hline 3 & 100 m. serbest yüzme & $(\% 60-70)$ & $1 \mathrm{dk}$. \\
\hline 4 & 50 m. Serbest yüzme & $(\% 70-80)$ & 30 sn \\
\hline 5 & $4 \times 25$ m. Serbest yüzme & $(\% 80-90)$ & Her 25 m. de 15 \\
& \multicolumn{3}{|c|}{ sn. dinlenme } \\
\hline 6 & 25 m. Serbest yüzme & $(\% 90-100)$ & sporculara \\
\hline \multicolumn{4}{|c|}{ Aktif toparlanma }
\end{tabular}

yüklenmeden sonraki ilk 5 dk. 10 dk. 20 dk. lar arasında yürüyüş yaptırıldıktan sonra ölçümler alındı.Masaj ile toparlanma için, yüklenmeden sonraki ilk 5 dk. 10 dk. 20 dk. lar arasında gönüllü sporcular masaj masasında yüz üstü yatırılıp alt ve üst ekstremitelere spor masajı yapıldı. Ölçümler masaj sonrası yapılarak elde edilen veriler kayıt altına alındı.Gönüllü sporcuların ölçümlerin yapıldığı esnada sandalyede oturur durumda ve rahat olması sağlandı. 
Araştırma için 20.01.2015 tarihinde Gaziosmanpaşa Üniversitesi Tıp Fakültesi Etik Kurulu tarafından onay alındı. Ayrıca araştırmaya katılan tüm gönüllüler aydınlatılmış onam formu ile bilgilendirildi ve araştırma için ilgili üniversiteden gerekli izinler alındı.

\section{Verilerin Analizi}

Sonuçların

değerlendirilmesinde

SPSS

20.0programı kullanıldı. Tüm değişkenlerin aritmetik ortalamaları, standart sapma değerleri, minimum ve maksimum değerleri hesaplandı. Dinlenme protokollerinin laktik asit ve kalp atımındaki farklılığı bulmak için bağımlı gruplarda tekrarlayan ölçümlerde iki yönlü varyans analizi (FRIDMAN) testi uygulandı. Anlamlılık düzeyi olarak 0.05 kabul edildi.

\section{BULGULAR}

\begin{tabular}{|l|c|c|}
\hline \multicolumn{2}{|c|}{ Tablo II. Sporculara ilişkin bazı fiziksel değişken ortalamaları. } \\
\hline & N & \pm SS \\
\hline Yaş (yıl & 15 & $23.20 \pm 2.69$ \\
\hline Boy(cm) & 15 & $179,20 \pm 7,26$ \\
\hline Kilo (kğ) & 15 & $80,20 \pm 10,29$ \\
\hline BKI & 15 & $25,03 \pm 2.45$ \\
\hline
\end{tabular}

Araştırmamıza katılan deneklerin yaş ortalaması $23.20 \pm 2.69$ yıl (20-28), boy uzunlu- ğu179,20 $\pm 7,26$ cm (170-196), beden ağırlığı 80,20 \pm 10,29 kg (63$100)$, beden kitle indeksleri $25,03 \pm 2.45$ olarak bulunmuştur.

Uygulanan aktif dinlenme ve masaj ile toparlanma yöntemlerinin yüklenme öncesi, yüklenme sonrası, 5 . dakika, 10. dakika ve 20. dakika ölçümlerin gurup içi karşılaştırmalarında kan laktik asit miktarına etkisinin, istatistiksel olarak anlamlı olduğu bulunmuştur ( $\mathrm{p}>0.05$ ).

Uygulanan aktif dinlenme ve masajile toparlanma yöntemlerinin yüklenme öncesi, yüklenme sonrası, 5. dakika, 10. dakika ve 20. dakika ölçümlerin gurup içi karşılaştırmalarında kalp atım sayısına etkisinin, istatistiksel olarak anlamlı olduğu bulunmuştur ( $p>0.05$ ).

Uygulanan aktif dinlenme ve masajile toparlanma yöntemlerinin yüklenme öncesi, yüklenme sonrası, 5 dakika, 10 dakika ve 20 dakika ölçümlerin gruplar arasında kan laktik asit miktarı açısından istatistiksel olarak anlamlı farklılığı olmadığı bulunmuştur ( $p>0.05)$.

Uygulanan aktif dinlenme ve masaj ile toparlanma yöntemlerinin yüklenme öncesi, yüklenme

\begin{tabular}{|l|c|c|c|c|c|c|}
\hline \multicolumn{6}{|l|}{ Tablo III. Farklı toparlanma yöntemlerinin kan laktik asit miktarına etkisinin grup içi karşıllaştıılması. } \\
\hline & Yüklenme Öncesi & Yüklenme Sonrası & 5 Dak. & 10 Dak. & 20 Dak. & p \\
\hline Aktif & $1,57 \pm 0,79$ & $13,26 \pm 3,31$ & $11,36 \pm 3,13$ & $8,67 \pm 3,56$ & $5,29 \pm 2,84$ & 0,000 \\
\hline Masaj & $1,48 \pm 0,51$ & $12,44 \pm 2,62$ & $10,60 \pm 2,88$ & $8,08 \pm 2,34$ & $4,84 \pm 1,51$ & 0,000 \\
\hline
\end{tabular}

$p<0.05$

\begin{tabular}{|l|c|c|c|c|c|c|}
\hline \multicolumn{6}{|l|}{ Tablo IV. Farklı toparlanma yöntemlerinin kalp atım sayısına etkisinin grup içi karşılaştııılması. } \\
\hline & Yüklenme Öncesi & Yüklenme Sonrası & 5 Dak. & 10 Dak. & 20 Dak. & p \\
\hline Aktif & $78,33 \pm 15,31$ & $134,20 \pm 10,9$ & $109,26 \pm 10,7$ & $109,06 \pm 7,57$ & $104,06 \pm 12,2$ & 0,000 \\
\hline Masaj & $76,13 \pm 15,51$ & $128,40 \pm 9,57$ & $108,93 \pm 10,7$ & $106,53 \pm 12,83$ & $102,86 \pm 13,42$ & 0,000 \\
\hline
\end{tabular}

\begin{tabular}{|c|c|c|c|c|c|}
\hline & Faktör 1 & Faktör 2 & $\pm S S$ & \pm SS & $p$ \\
\hline Yüklenme Öncesi & Aktif $^{3}$ & Masaj $^{\circ}$ & $1,57 \pm 0,79^{a}$ & $1,48 \pm 0,51^{\circ}$ & 0,917 \\
\hline Yüklenme Sonrası & Aktif $^{3}$ & Masaj $^{0}$ & $13,26 \pm 3,31^{\circ}$ & $12,44 \pm 2,62^{\circ}$ & 0,736 \\
\hline $5 . \mathrm{dk}$ & Aktif $^{3}$ & Masaj $^{\circ}$ & $11,36 \pm 3,13^{\mathrm{a}}$ & $10,60 \pm 2,88^{\circ}$ & 0,783 \\
\hline 10.dk. & Aktif $^{3}$ & Masaj $^{\circ}$ & $8,67 \pm 3,56^{\mathrm{a}}$ & $8,08 \pm 2,34^{\circ}$ & 0,855 \\
\hline $20 . \mathrm{dk}$ & Aktif $^{3}$ & Masaj $^{\circ}$ & $5,29 \pm 2,84^{\mathrm{a}}$ & $4,84 \pm 1,51^{\circ}$ & 0,849 \\
\hline
\end{tabular}




\begin{tabular}{|c|c|c|c|c|c|}
\hline & Faktör 1 & Faktör 2 & \pm SS & \pm SS & $P$ \\
\hline Yüklenme Öncesi & Aktif $^{3}$ & Masaj $^{\mathrm{D}}$ & $78,33 \pm 15,31^{a}$ & $76,13 \pm 15,51^{b}$ & 0,924 \\
\hline Yüklenme Sonrası & Aktif $^{3}$ & Masaj $^{0}$ & $134,20 \pm 10,59^{a}$ & $128,40 \pm 9,57^{\circ}$ & 0,246 \\
\hline $5 . \mathrm{dk}$ & Aktif ${ }^{3}$ & Masaj $^{0}$ & $109,26 \pm 10,17^{a}$ & $108,93 \pm 10,17^{\circ}$ & 0,996 \\
\hline 10.dk. & Aktif $^{3}$ & Masaj $^{\circ}$ & $109,06 \pm 7,57^{a}$ & $106,53 \pm 12,83^{\circ}$ & 0,796 \\
\hline 20. dk & Aktif $^{3}$ & Masaj $^{\circ}$ & $104,06 \pm 12,02^{a}$ & $102,86 \pm 13,42^{\circ}$ & 0,965 \\
\hline
\end{tabular}

a Faktör 1 Aktif Dinlenme b Faktör 2 Masaj Uygulaması ile Dinlenme

sonrası, 5 dakika, 10 dakika ve 20 dakika ölçümlerin gruplar arasında kalp atım sayısı açısından istatistiksel olarak anlamlı farklılığı olmadığı bulunmuştur $(p>0.05)$.

\section{TARTIŞMA VE SONUÇ}

Yüzme antrenmanlarının organizma üzerinde farklı boyutlarda etkisinin olacağı muhakkaktır. Yüzme antrenmanları sonucunda kalp atım sayısı ve kan laktik asit düzeylerine nasıl bir etki yaptığı ve toparlanma sürecinde farklı metotların kullanılmasının organizma üzerindeki etkileri ile ilgili araştırmaların yetersiz olduğu görülmektedir. Bu bağlamda bu çalışmanın alana açıklık getireceği ve katkı sağlayacağı düşünülmektedir.

Araştırmamızda elde ettiğimiz verilere göre uygulanan testin 5.dakikasında, 10.dakikasında ve 20.dakikasında laktik asit miktarı anlamlı bir şekilde azalma olduğu tespit edilmiştir. Yüklenme sonrası laktik asit miktarında ilk 10 dakika ki düşüşün 20.dakikaya göre daha fazla olduğu görülmüştür. Bu duruma göre yüklenme sonrası ilk 10 dakika içerisinde toparlanmanın daha hızlı olduğu düşünülmektedir. Çalışmamızda aktif toparlanma ile masaj ile toparlanma yöntemleri arasında istatistiksel olarak anlamlı farkılık olmadığı tespit edilmiştir. Fakat farklı toparlanma yöntemleri arasında istatistiksel olarak anlamlı fark olamamasına rağmen, toparlanma süresi açısından masaj ile toparlanma uygulamasının aktif toparlanmaya göre daha etkili olduğu düşünülmektedir.

Akkoyunlu (2002), ve arkadaşlarının 14-16 yaş amatör futbolcular üzerinde yapmış oldukları çalışmada kan laktik asit düzeylerinde maç önc esi, maç arası ve maç sonrasında anlamlı farklar tespit etmişlerdir (3).

Güzel (2002), 8 elit erkek plaj hentbol oyuncusu üzerinde yapmış olduğu çalışmada maçtan önce ve maçtan sonra almış olduğu glikoz, laktat ve kreatinkinaz (CK) düzeylerine ait bulgular arasında anlamlı artış olduğunu tespit etmiştir (6).

Kaya (1994), yaptığı bir çalışmasında kan laktik asit düzeyinin anlamlı bir artış gösterdiğini ve masaj+pasif dinlenme ile normal düzeyine dönüş eğiliminde olduğunu belirlemiştir. Dubrovsky (1983), alt ve üstekstremitelere 15-25 dakika süreyle masaj yaparak venlerdeki kan akısını tespit etmiş ve sonuçta masajın yüzeysel damarları genişleterek venlerde önemli derecede kan akışını hızlandırdığını, Bu durumun dinlenmeye olumlu etki ettiğini belitmiştir (11).

Birukov(1984), yaptığı araştırmada el masajı, su altı masajı ve gevşeme egzersizleri gibi yenilenme metotlarının güreşçilerde daha çabuk dinlenmeyi sağladığını belirtmişlerdir (4).

Gupta ve ark (1996), yaptıkları çalışmada kan laktatının yarılanma süresinin aktif dinlenmede (VO2max'ın \% 30'u) $15.7 \pm 2.5 \mathrm{dk}$, oturur pozisyondaki pasif dinlenmede $21.5 \pm 2.8 \mathrm{dk}$ ve kısa süreli bacak masajında $21.8 \pm 3.5 \mathrm{dk}$ olduğunu ve aktif dinlenmenin daha etkili olduğunu belirtmişlerdir (5).

Medbo ve ark (2006), yoğun egzersizden sonra dinlenme periyodunda kas laktatının \% 48'inin kana geçtiğini, \% 52'sinin kas içinde elimine edilerek glikojene dönüştürüldüğünü ifade etmiştir (13).

Ahmaidi ve ark (1996), yoğun egzersizler arasındaki aktif dinlenmenin (VO2max'ın \% 
32 'si) yüksek dirence karşı yapılan egzersizlerdeki kan laktat konsantrasyonunu azalttığını belirlemişlerdir (1).

Spierer ve arkadaşları (2004),yaptıkları bir çalışmada tekrarlanan Wingate testleri arasındaki 4 dakikalık aktif dinlenmelerin (VO2max'ın \%) pasif dinlenmeye göre yapılan toplam antrenmanı artırdığını ve antrenmanlı hokey oyuncularında kapiller kan laktatındaki azalmanın sedanterlere göre daha fazla olduğunu belirlemişlerdir (15).

Franchini ve ark (2003), yaptıkları araştırmada 5 dakikalık judo maçından sonra 15 dakikalık aktif dinlenmede kan laktatında anlamlı azalma olduğunu belirlemişlerdir (10).

Harbili ve arkadaşları (2007), aktif dinlenme ile pasif dinlenmenin 5 . ve 10.dakikalarında laktat konsantrasyonları açısından fark bulunmadığını ancak aktif dinlenme sırasında 5 . dakikadaki kan laktat konsantrasyonu (15.07 $\pm 2.83 \mathrm{mmol} / \mathrm{L})$ 10. dakikada (13.58 $\pm 2.97 \mathrm{mmol} / \mathrm{L})$ anlamlı şekilde azalmasına rağmen pasif dinlenmede (sırasıyla $14.34 \pm 3.16$ ve $14.06 \pm 3.07 \mathrm{mmol} / \mathrm{L}$ ) benzeri bir azalma olduğunu belirlemişlerdir.Bu sonuçlar aktif dinlenmenin kas içi laktatın kana geçişini hızlandırdığını ve diğer dokularda (kalp, karaciğer) elimine edildiğini gösteren bir bulgu olarak kabul edilebilir (8).

Öztürk (2008), yapmış olduğu çalışmada hentbolcuların müsabaka sonunda kontrol grubuna uygulanan 30 dakikalık pasif dinlenme ile deney grubuna uygulanan masaj uygulaması yapmış ve sporcuların kan laktik asit düzeylerinin aynı oranda normale dönme eğiliminde olduğu belirlemiştir (16). Bu durumun aralarındaki normale dönüş farkının 7-8 dakikalık alt ekstremite masajı ile 30 dakikalık pasif dinlenmenin arasındaki zaman farkındaki süreçten meydana geldiği düşünülebilir.Bu da sporcuya daha çabuk toparlanması için zaman kazandırabilir diyebilmek için daha çok sayıda ön ve son ölçümlerin geniş katılımlı farklı popülasyonlar üzerinde yapılmasını zorunlu kılmaktadır.

Yapılan birçok çalışmada aktif dinlenmenin kas içi laktatının kana geçişini hızlandırdığı, laktik asidi anlamlı düzeyde azalttığı ve diğer dinlenme uygulamalarına göre daha etkili olduğu ile ilgili sonuçlar görülmektedir.

Yaptığımız bu çalışmada ise yüzücülerde müsabaka ile birlikte oluşan laktik asidin literatürde de belirtilen şekilde aktif dinlenme ve masaj uygulamasıyla istirahat düzeyine yaklaştığı sonucu elde edilerek aralarında anlamlı farklılık bulunmamıştır.Yüzücülerde yapılan bu çalışmada anlamlı farkın olmamasının sebebi, yüzmenin vücutta rahatlatıcı masaj etkisi yapması bununla birlikte tüm vücut kaslarının aynı anda çalışması ile biriken laktik asidin daha hızlı uzaklaştırılması böylece antrenman sonrasında dinlenme uygulamalarına aynı düzeyde etki etmesini sağladığı düşünülmektedir.

Farklı dinlenme uygulamalarında test sonrası kalp atım sayısı değerleri arasında anlamlı farklılığ bulunmaması, test sonrası laktat cevaplarının benzerliği ile ilişkili fizyolojik verilerdir. Elde ettiğimiz değerlere göre test öncesi kan laktik asit miktarı normal iken testten hemen sonra pik yaptığı ve testten belirli zaman sonra orantılı olarak düşmeye başladığı ve normal seviyeye yaklaştığı görülmektedir. Buna göre literatürden elde ettiğimiz bulgular yapmış olduğumuz çalışma ile benzerlik göstermektedir.

Sonuç Olarak; Yüzücülere uygulanan yüzme antrenmanı sonrasında farklı dinlenme uygulamalarının laktat konsantrasyonları test öncesi değerleri normal iken, test bitiminin hemen sonrasında laktat seviyesi pik yapmıştır. Aktif ve masaj yöntemi ile yapılan dinlenme uygulamalarında kan laktik asitini uzaklaştırılması ile kalp atım sayısının düşmesi açısından aralarında anlamlı farklılık olmadığı belirlenmiştir. Fakat masaj uygulaması ile yapılan dinlenmenin kan laktik asitini uzaklaştırılmas ile kalp atım sayısının düşmesinde aktif dinlenme yöntemine göre daha etkili olduğu düşünülmektedir. $\mathrm{Bu}$ durumun masaj uygulamasının kan dolaşımını pasif şekilde artırarak kan laktatının hızla uzaklaşmasını sağladığından kaynaklandığı düşünülmektedir. 


\section{KAYNAKLAR}

1. Ahmaidi S, Granier P, Taoutaou Z, Mercier J, Du- bouchaud H, Prefaut $C$. Effects of active recovery on plasma lactate and anaerobic power following repeated intensive exercise. Med Sci Sports Exerc 1996; 28:450-6.

2. Akgün N, Egzersiz Fizyolojisi. 1986. 2. Baskı, İzmir

3. Akkoyunlu Y, Senel Ö, Güzel A.N. "Yıldız Erkek Futbolcuların Bir Müsabaka Süresinde Kan Laktat ve Kan Sekeri Düzeylerinin incelenmesi", 7. Uluslararası Spor Bilimleri Kongresi, 2002, Antalya-Kemer.

4. Bırukov A, Pocıosyan,M. Special Means ofRes- toration of Work Capacity of Wrestlers in the Periods Between Competitive Bouts, (Con- donsed), Sovied Sports Review, Vol. 19, No: 4, 191-192,12/1984

5. Gupta, G. Goswami A., Sadhukhan AK., Mathar DN., "Comparative study of lactate removal in short term massage of extremities, active recovery and a passive recovery period After supramaximal exercise sessions". 1996, Int J Sports Med (17:106-10.)

6. Güzel A.N. Eler S. "Bir Müsabaka Sürecinde Elit Erkek Plaj Hentbol Oyuncularının Kan Glikoz Laktat ve Kreatin Kinaz Düzeylerindeki Degisimler", 7. Uluslararası Spor Bilimleri Kongresi, 2002, Antalya-Kemer.

7. Harbili, E. Yoğun Egzersizden Sonra Aktif Dinlenmenin Laktik Asit Elimınasyonuna Etkisi, 1998. Yüksek Lisans Tezi, Selçuk Üniversitesi, Konya

8. Harbili E. "Yoğun egzersizden sonra aktif dinlenmenin kan laktat eliminasyonuna etkileri" 2007.Genel Tıp Derg (;17-4)
9. Fox E. The Physiological Basis of Phtsical Education and Atletics. (1988). 4 th edition, Saunders College Publiohing, Philadelphia.

10. Franchini E, Yuri Takito M, Yuzo Nakamura F, Ayumi Matsushigue K, Peduti Dal'Molin Kiss MA. Effects of recovery type after a judo combat on blood lactate removal and on performance in an intermittent anaerobic task. J Sports Med Phys Fitness 2003; 43:424-31.

11. Kaya M. Masajın Egzersiz Sonrası Toparlanmaya Etkisi (1994); G.Ü. Saglık Bilimleri Enstitüsü Beden Egitimi ve Spor Anabilim Dalı, Doktora Tezi.

12. Kirkendal DT. Mechanism of Peripheral Fatique. Med. and sci, in Sports and Exercise 1990 . Vol. 22, No: 4, U.

S. A. , $444-449$,

13. Medbo, J.I., And Tabata, T. Anaerobic energy release in working muscle during 30 to $3 \mathrm{~mm}$ of exhausting bicycling. J.Appl.Physiol 1993. (75, 4, 1654-1660).

14. Stupnicki R, Gabrys T, Szmatlan UG, Tomaszewski P. Fitting a single-phase model to the post-exercise changes in heart rate and oxygen uptake. Physiological Research, 2010. 59, 357- 362.

15. Spierer DK, Goldsmith R., Baran DA., Hryniewicz K., Katz SD. "Effects of active vs. passive recovery on work performed during serial supramaximal exercise tests". Int J Sports Med 2004, (25:109-14).

16. Öztürk M. Edirne Büyük Erkekler Hentbol Ligine Katılan Takımların Müsabaka Öncesi ve Sonrası Laktik Asit Düzeylerinin Belirlenmesi ve Masaj Uygulamasının Olası Etkilerinin Arastırılması, Yüksek Lisans Tezi. 2008. 